\title{
Hubungan Kemampuan Berpikir Kreatif Melalui Model Mind Mapping dengan Hasil Belajar Siswa Sekolah Dasar
}

\author{
Siti Aulia Febriyanti ${ }^{1}$, Fitria Wulandari ${ }^{2}$ \\ ${ }^{1,2}$ Fakultas Psikologi dan Ilmu Pendidikan Universitas Muhammadiyah Sidoarjo
}

Email : auliafebriyanti92@gmail.com

\begin{abstract}
ABSTRAK
Penelitian ini bertujuan untuk mengetahui adanya hubungan yang positif dan signifikan antara berpikir kreatif melalui model mind mapping dengan hasil belajar siswa sekolah dasar. Metode penelitian ini adalah kuantitatif dengan jenis penelitiannya yaitu penelitian korelasi. Sampel dalam penelitian ini siswa kelas IV di SD Muhammadiyah 8 Tulangan yang berjumlah 28 siswa. Teknik pengumpulan data berasal dari observasi kemampuan berpikir kreatif melalui model pembelajaran mind mapping dan tes berupa soal pilihan ganda. Berdasarkan hasil analisis data, hasil penelitian yang diperoleh yaitu analisis korelasi serhana (r) sebesar 0,645 dan uji signifikan koefisien korelasi sederhana (Uji t) yaitu $t_{\text {hitung }}>$ $\mathrm{t}_{\text {tabel }}(4,303>2,056)$ dan signifikansi $(0,001<0,05)$. Hasil penelitian menunjukkan bahawa terdapat hubungan yang positif dan signifikan antara berpikir kreatif melalui model mind mapping dengan hasil belajar siswa sekolah dasar, karena hasil analisis korelasi sederhana (r) positif berarti semakin tinggi kemampuan berpikir kreatif melalui model pembelajaran mind mapping maka semakin meningkatkan hasil belajar, hal tersebut dapat dipercaya dengan tingkat kepercayaan sebesar $95 \%$ atau taraf signifikansi 0,05 .
\end{abstract}

Kata kunci : Berpikir Kreatif; Pembelajaran Mind Mapping; Hasil Belajar

\section{ABSTRACT}

This study aims to determine the existence of a positive and significant relationship between creative thinking through the mind mapping model and the learning outcomes of elementary school students. This research method is quantitative with the type of research that is correlation research. The sample in this study was fourth grade students at SD Muhammadiyah 8 Tulangan, totaling 28 students. The data collection technique was derived from the observation of creative thinking skills through mind mapping learning models and tests in the form of multiple choice questions. Based on the results of data analysis, the research results obtained are simple correlation analysis ( $r$ ) of 0.645 and significant test of simple correlation coefficient $(t$ test) namely tcount $>$ ttable $(4.303>2.056)$ and significance (0.001 0.05). The results of the study indicate that there is a positive and significant relationship between creative thinking through the mind mapping model and the learning outcomes of elementary school students, because the results of a positive simple (r) correlation analysis mean that the higher the ability to think creatively through the mind mapping learning model, the higher the learning outcomes. it can be trusted with a confidence level of $95 \%$ or a significance level of 0.05 .

Keywords: Creative Thinking ; Mind Mapping Learning ; Learning Outcomes

(C) 2021 Siti Aulia Febriyanti1, Fitria Wulandari2

Under the license CC BY-SA 4.0

Pedagogika.fip@ung.ac.id P-ISSN: 2086-4469 E-ISSN: 2716-0580 


\section{PENDAHULUAN}

Pendidikan merupakan usaha sadar dan terencana untuk mewujudkan suasana belajar dan proses pembelajaran agar peserta didik secara aktif mengembangkan potensi dirinya. Tujuan pendidikan Nasional berfungsi mengembangkan kemampuan dan membentuk watak serta peradaban bangsa agar menjadi manusia beriman dan taqwa kepada Tuhan Yang Maha Esa, berakhlak mulia, cakap, kreatif, mandiri, menjadi warga negara yang demokrasi sehingga bertanggung jawab (Undang-Undang Republik Indonesia Nomor 20 Tahun 2003) tentang Sistem Pendidikan Nasional.

Pendidikan pada abad-21 menuntut lahirnya generasi unggul yang berpikir kreatif, sehingga guru harus mampu menciptakan lingkungan belajar yang mampu mengembangkan kemampuan berpikir kreatif. Pernyataan tersebut sejalan dengan pendapat (Fitriyah, Hariani, \& Fikri, 2015) bahwa kemampuan berpikir kreatif dibutuhkan dalam setiap perkembangan dunia pendidikan, karena pada abad 21 terjadi perubahan struktur tenaga kerha dan karakter tenaga kerakter tenaga kerja segingga menuntut untuk lebih kreatif dalam menciptakan solusi baru atau cara baru dalam menyampaikan gagasan, menemukan prinsip baru, mampu kerjasama dalam kelompok untuk memecahkan masalah, menghasilkan jasa maupun produk-produk baru.

Kemampuan berpikir kreatif adalah kemampuan yang memberikan kemungkinan jawaban yang bermacammacam berdasarkan informasi yang diberikan untuk mengembangkan suatu masalah menjadi alternatif jawaban (Mardhiyana \& Sejati, 2016). Kemampuan berpikir kreatif mempunyai indikator yaitu kemampuan beripikir lancar (fluency), kemampuan berpikir luwes (flexibility), kemampuan berpikir orisinal (originality) dan kemampuan berpikir terperinci (elaboration) (Yusnaeni, Susilo, Corebima \& Zubaidah, 2016).

Semua siswa mempunyai kemampuan berpikir kreatif, namun hanya sebagian siswa yang mampu memanfaatkan kemampuan berpikir kreatif yang dimilikinya. Kemampuan berpikir kreatif dapat dikembangkan melalui proses pembelajaran dengan cara siswa dilibatkan secara aktif dalam proses pembelajaran. Model yang tepat untuk mengembangkan 
kemampuan berpikir kreatif siswa adalah model mind mapping.

Pernyataan tersebut didukung dalam jurnal (Wulandari, Mawardi \& Wardani 2019) bahwa kemampuan berpikir kreatif siswa dapat meningkan dengan menggunakan model mnd mapping, hal ini dapat dibuktikan dengan rata-rata presentase siklus I meningkat menjadi $33,3 \%$ dan pada siklus II meningkat menjadi $61,9 \%$.

Mind mapping merupakan cara mencatat yang efektif, efisien, kreatif, menarik, dan mudah, karena dilakukan dengan cara memetakan pikiran-pikiran (Buzan, 2012 : 4). Model pembelajaran mind mapping merupakan model pembelajaran yang menggunakan cara mencatat yang kreatif, dapat mengembangkan kemampuan siswa berpikir kreatif maupun mengingat materi dalam pembelajaran (Fitriyah et al., 2015).

Siswa yang memiliki kemampuan berpikir kreatif dengan baik maka hasil belajar siswa juga meningkat. Pernyataan tersebut sesuai dengan pendapat (Supardi, 2015). Hasil belajar adalah kemampuan yang diperoleh siswa setelah melalui proses pembelajaran (Sudjana, $2014 ; 22$ ).
Berdasarkan hasil wawancara dengan guru kelas IV di SD Muhammadiyah 8 Tulangan, diperoleh informasi bahwa guru menerapkan model mind mapping untuk membantu mengembangkan kemampuan berpikir kreatif siswa dengan cara siswa menemukan alternatif jawaban dari permasalahan yang diberikan oleh guru melalui teknik mencatat dalam bentuk peta pikiran.

Dari uraian di atas, peneliti menyimpulkan bahwa dalam proses pembelajaran semua komponen harus saling terhubung maupun berkaitan satu sama lain. Berdasarkan uraian di atas, peneliti ingin mengetahui adanya hubungan antara kemampuan berpikir kreatif melalui model mind mapping dengan hasil belajar. Sehingga peneliti melakukan penelitian dengan judul Hubungan Berpikir Kreatif Melalui Model Mind Mapping dengan Hasil Belajar Siswa Sekolah Dasar.

\section{METODE PENELITIAN}

Penelitian ini menggunakan metode penelitian kuantitaf dengan jenis penelitiannya yaitu penelitian korelasi. Penelitian korelasi dalam ilmu statistik

\section{Pedagogika.fip@ung.ac.id $\quad P-I S S N$ : 2086-4469 E-ISSN: 2716-0580}


diartikan sebagai penelitian yang dilakukan untuk mengetahui hubungan antar dua variabel atau lebih (Anas, 2014 :179). Pengambilan sampel dalam penelitian ini menggunakan teknik nonproblatility sampling yaitu teknik pengambilan sampek yang tidak memberi kesempatan sama bagi setiap anggota populasi untuk dipilih menjadi sampel (Sugiyono, 2018 :133), dengan jenis sampling total atau sensus yaitu teknik penentuan sampel bila semua Uji hipotesis menggunakan perhitungan aplikasi SPSS 20 pada uji normalitas, uji linieritas menggunakan Test for Linearty pada taraf signifikansi 0,05 dan analisis data menggunakan analisis korelasi sederhana Product Moment Pearson. Signifikansi hubungan dihitung menggunakan uji signifikansi koefisian korelasi sederhana (uji t). anggota populasi digunakan sebagai sampel (Sugiyono, 2018 : 139). Sampel dalam penelitian ini adalah siswa kelas IV di SD Muhammadiyah 8 Tulangan yang berjumlah 28 siswa. Teknik pengumpulan data kemampuan berpikir kreatif melalui model mind mapping variabel (X) menggunakan observasi dan hasil belajar variabel (Y) menggunakan hasil nilai siswa yang berupa soal pilihan ganda.

\section{HASIL DAN PEMBAHASAN}

\section{Hasil Penelitian}

Berdasarkan dari data observasi dan hasil belajar, kemudian dihitung uji normalitas data untuk kemampuan berpikir kreatif melalui model mind mapping (X) dengan hasil belajar (Y) dengan menggunakan SPSS 20 sebagai berikut :

\section{Tabel 1. Hasil Uji Normalitas Data}

\begin{tabular}{ccccccccc}
\hline a. Lilliefors Significance Correction & \multicolumn{3}{l}{ Tests of Normality } & & & \\
\hline & \multicolumn{2}{c}{ Kolmogorov-Smirnov } & & \multicolumn{3}{c}{ Shapiro-Wilk } & \\
\cline { 2 - 9 } & Statistic & df & Sig. & Statistic & df & Sig. \\
\hline $\begin{array}{c}\text { Kemampuan Berpikir } \\
\text { Kreatif Melalui Model } \\
\text { Mind Mapping }\end{array}$ & .155 & 28 & .085 & .911 & 28 & .021 \\
\hline Hasil Belajar & .147 & 28 & .125 & .930 & 28 & .063 \\
\hline
\end{tabular}

Tabel 1 di atas menunjukkan bahwa hasil dari uji normalitas data kemampuan berpikir kreatif melalui model mind mapping nilai signifikansi sebesar 0,085, sedangkan data hasil belajar nilai sigfinikansi sebesar 0,125 . Karena

\section{Pedagogika.fip@ung.ac.id $\quad P-I S S N$ : 2086-4469 E-ISSN: 2716-0580}


PEDAGOGIKA

Volume 12 (Nomor 2) 2021

HaL. 152-160

signifikansi data lebih besar dari 0,05 maka dapat disimpulkan bahwa populasi data berpikir kreatif melalui model mind mapping dan hasil belajar berdistribusi normal.

Tabel 2. Hasil Uji Linieritas

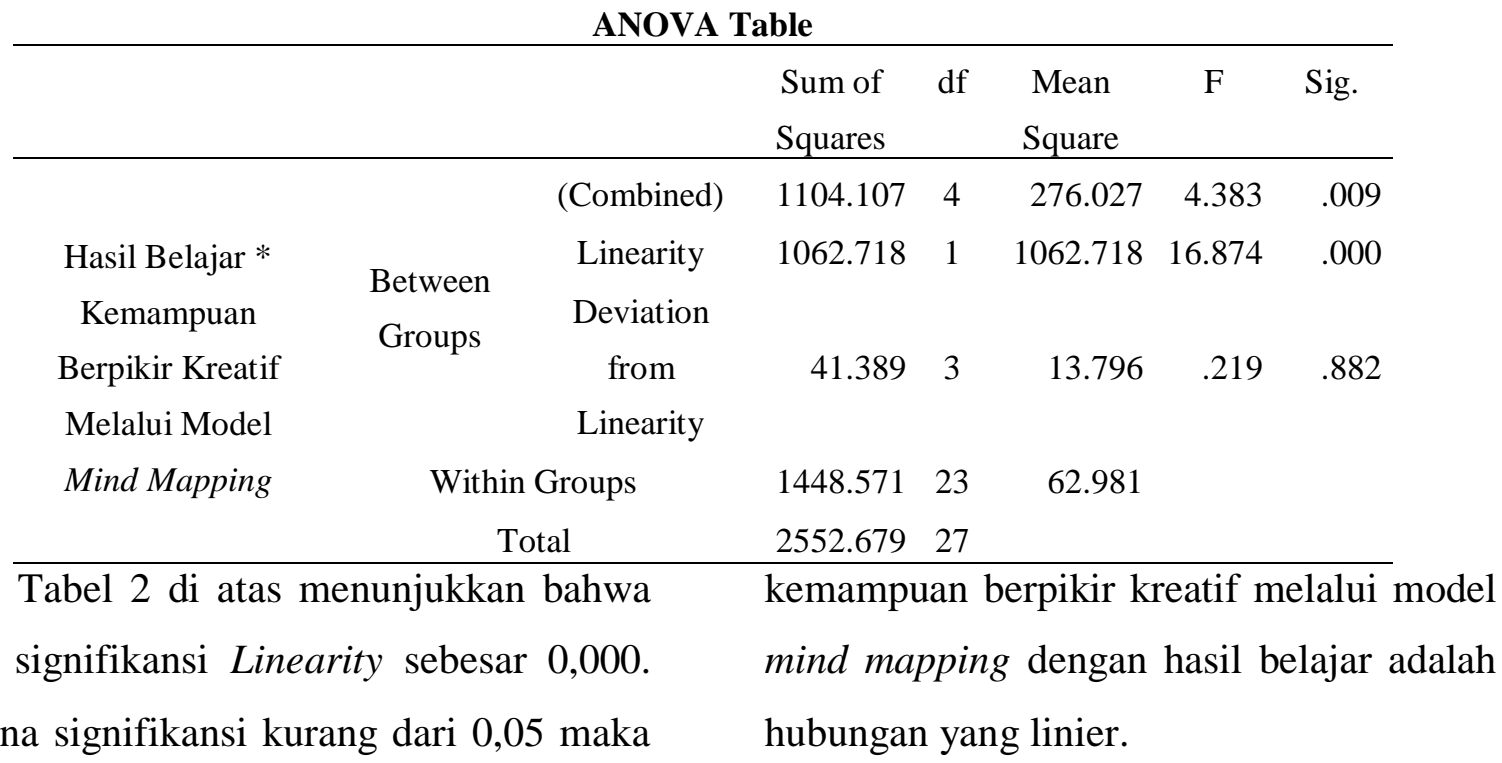

dapat disimpulkan bahwa antara

Tabel 3. Analisis Korelasi Sederhana

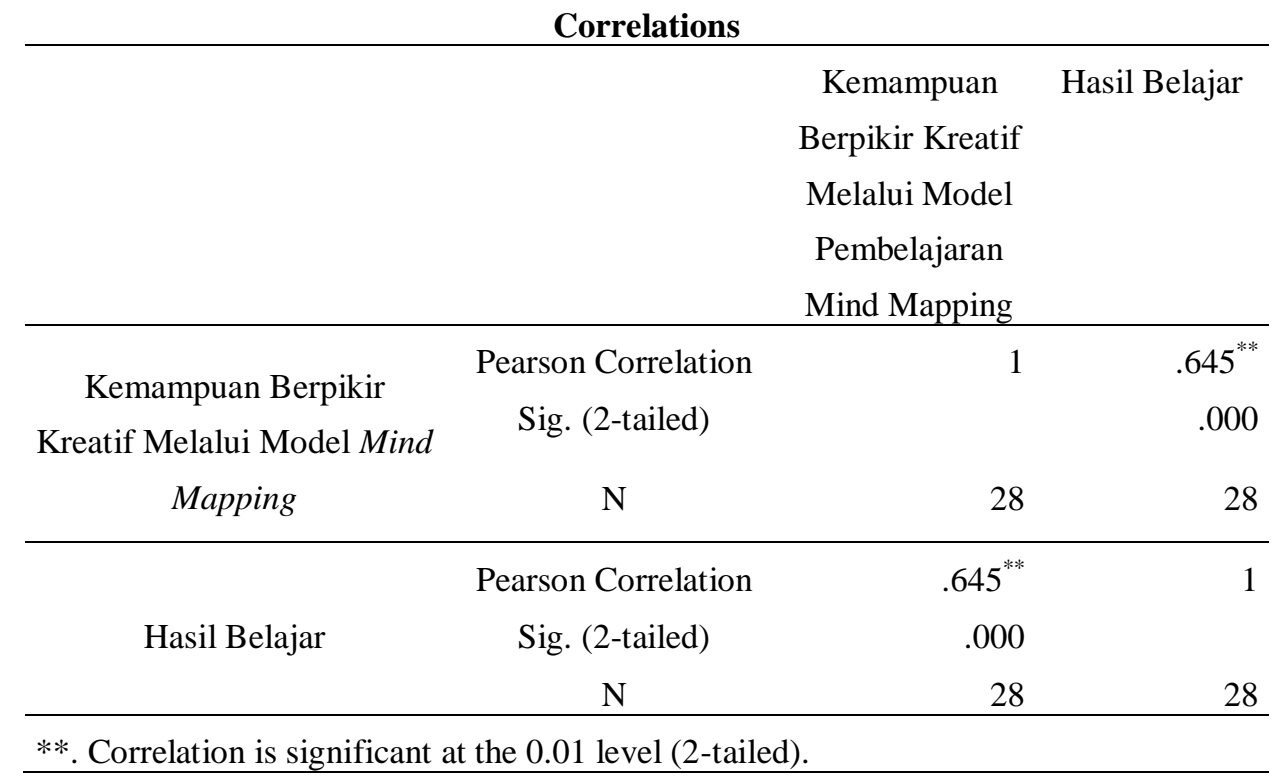

Pedagogika.fip@ung.ac.id $\quad P-I S S N$ : 2086-4469 E-ISSN: 2716-0580 
Berdasarkan tabel diatas hasil analisis korelasi sederhana (r) terdapat korelasi antara berpikir kreatif melalui model mind mapping dengan hasil belajar (r) sebesar 0,645. Berdasarkan hasil analisis korelasi sederhana (r) maka, arah hubungan antara kemampuan berpikir kreatif melalui model mind mapping dengan hasil belajar adalah positif artinya terdapat hubungan yang searah antara variabel $\mathrm{X}$ dan variabel $\mathrm{Y}(\mathrm{X}$ naik, maka $\mathrm{Y}$ naik) atau karena nilai $\mathrm{r}$ positif. Untuk lebih jelasnya arah hubungan dapat dilihat pada diagram batang di bawah ini :

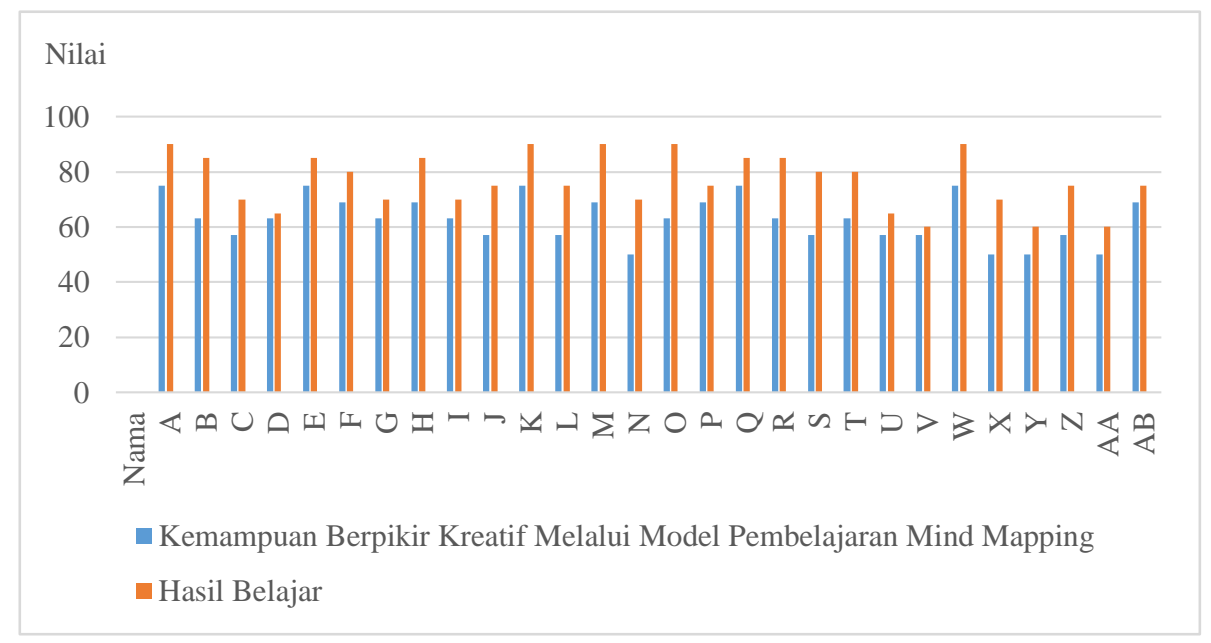

Gambar 1. Diagram Arah Hubungan

Uji signifikansi koefisien korelasi sederhana (uji t), menggunakan uji 2 sisi dengan tingkat signifikansi 5\%, dengan menggunakan rumus sebagai berikut :

$$
\mathrm{t}_{\text {hitung }}=\frac{r \sqrt{n-2}}{\sqrt{1-r^{2}}}
$$

Berdasarkan perhitungan $t_{\text {hitung }}$ dan $\mathrm{t}_{\text {tabel }}$ diperoleh hasil bahwa $\mathrm{H}_{0}$ ditolak hal ini dapat dibuktikan bahwa nilai $t_{\text {hitung }}>t_{\text {tabel }}$
$(4,303>2,056)$ dan signifikansi $(0,001<$ 0,05), maka $\mathrm{H}_{0}$ ditolak, artinya bahwa ada hubungan secara signifikansi antara kemampuan berpikir kreatif melalui model mind mapping dengan hasil belajar.

\section{Pembahasan}

Berdasarkan hasil penelitian menunjukkan bahwa terdapat hubungan yang. positif dan. signifikan antara kemampuan berpikir kreatif. melalui model

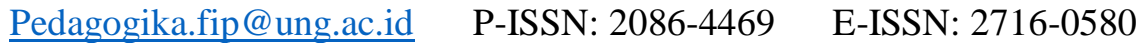


mind mapping dengan. hasil belajar. Model mind mapping dapat meningkatkan kemampuan berpikir kreatif dan hasil belajar siswa, siswa dapat mengembangkan ide-ide atau gagasan untuk menyelesaikan masalah dengan menggunakan mind

Arah hubungan antara kemampuan berpikir kreatif melalui model mind mapping dengan hasil belajar adalah positif berarti terdapat hubungan yang searah antara variabel $\mathrm{X}$ dan variabel $\mathrm{Y}$ (X naik, maka Y naik) (Priyatno, 2011 :16) atau karena nilai $r$ positif berarti semakin tinggi kemampuan berpikir kreatif melalui model korelasi sederhana (Uji t) yaitu $t_{\text {hitung }}>t_{\text {tabel }}$ $(4,303>2,056)$ dan signifikansi $(0,001<$ $0,05)$

Hasil penelitian ini didukung dengan jurnal (Acesta, 2020), bahwa model mind mapping berpengaruh pada kemampuan berpikir kreatif siswa, hal ini dapat dibuktikan dengan hasil pretest diperoleh rata-rata 45,42 dan pada posttest diperoleh rata-rata nilai 83,79 .

Kemampuan berpikir kreatif siswa bisa dikembangkan melalui proses pembelajaran yaitu dengan cara guru menerapkan model mind mapping. Hasil dari mind mapping siswa di observasi oleh mapping, dengan cara siswa menemukan alternatif jawaban dari permasalahan yang diberikan oleh guru melalui teknik mencatat dalam bentuk mind maping (peta pikiran).

mind mapping maka semakin meningkatkan hasil belajar, hal ini dapat dibuktikan dengan hasil analisis korelasi sederhana (r) positif sebesar 0,645. Hal tersebut dapat dipercaya dengan tingkat kepercayaan sebesar $95 \%$ atau taraf signifikansi 0,05 , hal ini bisa dibuktikan dengan hasil uji signifikan koefisien observer untuk melihat ada atau tidaknya 4 indikator dari kemampuan berpikir kreatif dalam hasil mind mapping siswa.

Semakin baik kemampuan berpikir kreatif melalui model pembelajaran mind mapping maka semakin meningkatkan hasil belajar, sejalan dengan pendapat (Supardi, 2015) bahwa berpikir kreatif kreatif berperan positif dalam meningkatkan hasil belajar kognitif siswa. Hasil belajar dalam penelitian berupa tes tulis dengan bentuk soal pilihan ganda yang dikerjakan siswa di akhir pembelajaran setelah siswa melakukan proses pembelajaran. 


\section{SIMPULAN}

Berdasarkan data 28 siswa kemampuan berpikir kreatif melalui model mind mapping (variabel $\mathrm{X}$ ) dan hasil belajar (variabel Y), hasil penelitian serta pembahasan dapat disimpulkan bahwa terdapat hubungan positif dan signifikansi antara kemampuan berpikir kreatif melalui model pembelajaran mind. mapping. dengan. hasil belajar siswa sekolah dasar.

\section{REFERENSI}

Acesta, A. (2020). Pengaruh Penerapan Metode Mind Mapping Terhadap Kemampuan Berpikir Kreatif Siswa. NATURALISTIC: Jurnal Kajian Penelitian Pendidikan Dan Pembelajaran, 4(2b), 581-586. https://doi.org/10.35568/naturalistic.v4 i2b.766

Buzan, Tony, (2012). Buku Pintar Mind Map (Cetakan Kesepuluh). Jakarta: PT. Gramedia Pustaka Utama.

Darusman, R. (2014). Penerapan Metode Mind Mapping (Peta Pikiran) Untuk Meningkatkan Kemampuan Berpikir Kreatif Matematik Siswa Smp. Infinity Journal, $\quad 3(2), \quad 164$. https://doi.org/10.22460/infinity.v3i2.6 1

Fitriyah, N., Hariani, S. A., \& Fikri, K. (2015). Pengaruh Model Pembelajaran Creative Problem Solving Dengan Mind Mapping Terhadap Kemampuan
Berpikir Kreatif Dan Hasil Belajar Ipa Biologi. Jurnal Edukasi, 11(2), 44-50. http://repository.unej.ac.id/bitstream/ha ndle/123456789/65672/Ainul Latifah101810401034.pdf?sequence $=1$

Mardhiyana, D., \& Sejati, E. O. W. (2016). Mengembangkan Kemampuan Berpikir Kreatif dan Rasa Ingin Tahu Melalui Model Pembelajaran Berbasis Masalah. PRISMA, Prosiding Seminar Nasional Matematika, 1(1), 672-688.

Sarifudin, \& Evendi, H. (2020). Jurnal Mitra Pendidikan ( JMP Online ). Jurnal Mitra Pendidikan, 4(1), 1-9. http://www.ejurnalmitrapendidikan.com/index.php/e -jmp/article/view/737/473

Sudijono, Anas. (2014). Pengantar Statistik Pendidikan Edisi 1. Jakarta: Rajawali Pers.

Sudjana, Nana. (2014). Penilaian Hasil Proses Belajar Mengajar (Ceratakan Kedelapanbelas). Bandung : PT. Remaja Rosdakarya.

Sulichah, E. (2018). Efektivitas model pembelajaran mind mapping terhadap hasil belajar ipa ditinjau dari motivasi belajar siswa. Natural: Jurnal Ilmiah Pendidikan IPA, 5(2), 71. https://doi.org/10.30738/natural.v5i2.2 965

Supardi. (2015). Peran Berpikir Kreatif Dalam Proses Pembelajaran Matematika. Jurnal Formatif 2(3), 248-262. 
Sugiyono. (2018). Metode Penelitian Kuantitatif. Bandung : Alfabeta.

Wulandari, F. A., Mawardi, M., \& Wardani, K. W. (2019). Peningkatan Keterampilan Berpikir Kreatif Siswa Kelas 5 Menggunakan Model Mind Mapping. Jurnal Ilmiah Sekolah Dasar, $3(1)$, 10. https://doi.org/10.23887/jisd.v3i1.1717 4

Yusnaeni, Susilo, H., Corebima, A. D., \& Zubaidah, S. (2016). Hubungan Kemampuan Berpikir Kreatif dan Hasil Belajar Kognitif pada Pembelajaran Search Solve Create and Solve di SMA. Prosiding Seminar Nasional Biologi 2016, January 2018, 443-446. 